\title{
The roles of CCR6 in migration of Th17 cells and regulation of effector T-cell balance in the gut
}

\author{
C Wang ${ }^{1,3}$, SG Kang ${ }^{1,3}$, Lee $^{1}$, Z Sun ${ }^{2}$ and CH Kim ${ }^{1}$
}

\begin{abstract}
Migration and trafficking receptors of Th17 cells to mucosal tissues have been unclear. We report that Th17 cells preferentially migrate to the intestine and associated lymphoid tissues, and CCR6 is the homing receptor important for Th17 cell migration to certain tissue microenvironments of the intestine such as Peyer's patches and other sites where its ligand CCL2 0 is expressed. We found the cytokine transforming growth factor- $\beta 1$ is required for CCR 6 expression whereas IL-2 suppresses it. CCR6-deficient Th17 cells aberrantly migrate to different compartments of the intestine. Surprisingly, administration of CCR6-deficient Th17 cells into severe combined immunodeficiency (SCID) mice led to excessive intestinal inflammation with increased Th1 but decreased Th17 cells and FoxP3 ${ }^{+} \mathrm{T}$ cells. In addition, CCR6 deficiency led to aberrantly widespread effector T cells in the inflamed intestine of the SCID mice. We conclude that CCR6 regulates Th17 cell migration to the gut and effector T-cell balance/distribution in inflamed intestine.
\end{abstract}

\section{INTRODUCTION}

Th17 cells are effector $\mathrm{T}$ cells that characteristically express interleukin (IL)-17A, IL-17F, IL-21, and IL-22. ${ }^{1-6}$ IL-17A and IL-17F are important in inflammation and host defense by inducing cytokines (IL-6, GM-CSF, G-CSF) and chemokines. ${ }^{7-9}$ IL-21 broadly regulates innate and acquired immune responses and promotes the generation of Th17 cells, ${ }^{10-12}$ and IL-22 has both inflammatory and antiinflammatory functions and induces antimicrobial proteins and lipopolysaccharidebinding protein. ${ }^{13-16}$ Thus, Th17 cells are thought to have diverse functions in regulation of inflammation and immune responses. Th17 cells are induced from naive $\mathrm{T}$ cells during antigen priming in the presence of certain cytokines such as IL-6, transforming growth factor (TGF)- $\beta 1$, and IL-23. ${ }^{17-20}$ In generation of Th17 cells, STAT3, ROR- $\gamma \mathrm{t}$, and ROR- $\alpha$ are implicated. ${ }^{21-24}$ STAT3 is activated downstream of IL- 6 and induces ROR- $\alpha$, and ROR- $\gamma \mathrm{t}$ is an orphan nuclear receptor and is involved also in survival of thymocytes and lymphoid tissue inducer cells. ${ }^{25-27}$ Certain cytokines such as IL-2728,29 and IL-2 ${ }^{30}$ suppress the induction of Th17 cells.

Th17 cells are highly enriched in the intestine. The enrichment of Th17 cells in the intestine may be due to their induction/ expansion in the intestine or homing of Th17 cells into the intestine. In terms of induction and expansion, it has been reported that mucosal dendritic cells can produce inflammatory cytokines such as tumor-necrosis factor- $\alpha$ (TNF- $\alpha$ ), IL-6, IL-12p40, and IL-23p19 upon stimulation with lipopolysaccharide ${ }^{31}$ and can induce Th17 cells in vitro. ${ }^{32}$ In terms of homing, however, it is not clear which trafficking receptor is important for the migration of Th17 cells to the gut. It has been reported that Th17 cells in mice and humans express various trafficking receptors such as CCR2, CCR4, CCR5, CCR7, CCR8, CCR10, CXCR4, CXCR5, CXCR6, and L-selectin. ${ }^{33-37}$ Among the receptors, CCR6 is characteristically expressed by both human and mouse Th17 cells.

To gain more insights into the molecular basis for the intestine-specific tissue tropism of Th17 cells, we took a systematic approach to identify and determine the function of the major trafficking receptors of Th17 cells. Although Th17 cells express many trafficking receptors in a tissue-specific manner, CCR6 is the only receptor that is uniformly expressed by all subsets of Th17 cells. We found that regulation of CCR6 expression is coordinately regulated by TGF- $\beta 1$ and IL-2. Although CCR6 is not required for long-term population of Th17 cells in the intestinal lamina propria of normal hosts, CCR6 is required for migration of Th17 cells in Peyer's patches (PPs) and other related tissue sites of the intestine where CCL20 is expressed. We also present data that CCR6 regulates effector T-cell balance and distribution in inflamed intestinal lamina propria; and it has a positive function in prevention of excessive inflammation in the intestine.

\footnotetext{
${ }^{1}$ Laboratory of Immunology and Hematopoiesis, Department of Comparative Pathobiology, Purdue Cancer Center, Bindley Bioscience Center, Purdue University, West Lafayette, Indiana, USA. 2Division of Immunology, Beckman Research Institute of the City of Hope, Duarte, California, USA. ${ }^{3}$ These two authors contributed equally to this work. Correspondence: CH Kim (chkim@purdue.edu) 


\section{RESULTS \\ Th17 cells and FoxP3 ${ }^{+}$T cells are differentially distributed in the body}

It has been reported that many Th17 cells are found in the gut but the exact distribution of Th17 cells in the intestine vs. other tissue sites has not been determined. We examined the tissue distribution of Th17 cells in young (5- to 7-week old) BALB/C mice (Figure 1a). We examined also the distribution of FoxP3 ${ }^{+}$ $\mathrm{T}$ cells for comparison because Th17 cells and FoxP ${ }^{+} \mathrm{T}$ cells are the two important T-cell subsets that share certain features in development but have different functions. Th17 cells were identified by staining for expression of intracellular IL-17A (hereafter referred to as IL-17), and FoxP ${ }^{+}$T cells were examined by intranuclear staining of FoxP3. Although FoxP3 ${ }^{+}$cells were present in secondary lymphoid tissues at significant frequencies ( $\sim 10 \%$ of $\mathrm{CD}^{+}{ }^{+} \mathrm{T}$ cells), Th17 cells were scarce in mesenteric lymph nodes, peripheral lymph nodes, and spleen. Instead, most Th17 cells were found in the intestine and PPs. Some Th17 cells were found also in nonlymphoid tissues such as peritoneal cavity (PC) and liver. In percentage distribution among the selected organs, most Th17 cells were present in the small intestine (SI), PP, liver, and mesenteric lymph node (Supplementary Figure 1). Thus, Th17 cells have a tissue tropism relatively more specific for the gut and associated lymphoid tissues.

\section{Th17 cells and FoxP3+ cells migrate differently in vivo}

The high prevalence of Th17 cells in the gut and associated lymphoid tissues suggests that Th17 cells would be induced from naive $\mathrm{T}$ cells, expand in numbers, and/or migrate to the tissues. It is likely that all of these processes are important for the enrichment of Th17 cells in the gut. The possibility that Th17 cells can be induced by antigen-presenting cells in the gut has been raised by the discovery that dendritic cells can convert naive T cells into Th17 cells in vitro. ${ }^{32}$ To separately examine the migratory ability of Th17 cells apart from the process of induction/expansion, we performed a short-term $(20 \mathrm{~h})$ homing assay for in vitro-generated Th17 cells (Figure $\mathbf{1 b}$ and c). Again, the FoxP3 ${ }^{+}$T cells, similarly generated with IL- 2 and TGF- $\beta 1$ in vitro, were included for comparison. Th17 cells migrated well to PP, PC, and large intestinal lamina propria (LI), whereas FoxP $3^{+} \mathrm{T}$ cells migrated very well to peripheral lymph node, and marrow (Figure 1 $\mathbf{b}$ and $\mathbf{c}$ ). In contrast, Th17 cells poorly migrated to peripheral lymph node. Both Th17 cells and FoxP3 ${ }^{+}$ T cells can migrate to spleen, SI, and liver at similar rates. Thus, Th17 cells and FoxP3 ${ }^{+}$T cells are quite different from each other in short-term homing behavior.

\section{In vivo-generated Th17 cells are heterogeneous in expression of trafficking receptors}

Th17 cells are known to express CCR6 $6^{34,35,37,38}$ but the exact trafficking receptor phenotype of Th17 cells has been debated. Migration of T cells is regulated by trafficking receptors such as chemokine receptors and adhesion molecules. Therefore, we examined the chemokine receptors expressed by the Th17 cell subsets of selected organs (PP, spleen, SI, and large intestine (LI)) (Figure 2; Supplementary Figure 2). We also examined the chemokine receptors that are expressed by control $\mathrm{CD} 4^{+} \mathrm{T}$ cells subsets $\left(\mathrm{CD} 62 \mathrm{~L}^{+} \mathrm{CD} 44^{-}\right.$naive and CD62L ${ }^{-} \mathrm{CD} 44^{+}$non-Th17 memory T cells; and FoxP3 ${ }^{+}$cells) for comparison (Figure 2). Th17 cells of the four organs differentially expressed the chemokine receptors such as CCR4 (Th2 associated), CCR7 (lymphoid tissue homing), CCR9 (SI homing), and CXCR5 (B-cell follicle homing). CCR4 was expressed by colonic Th17 cells but not by small intestinal Th17 cells. CCR7 and CXCR5 were highly expressed by splenic and PP Th17 cells but expressed by fewer Th17 cells of small and LI. In contrast, CCR9 was more preferentially expressed by intestinal Th17 cells than splenic Th17 cells. CCR6 is the chemokine receptor universally expressed by the Th17 cells of the all four organs. In contrast, the FoxP3 ${ }^{+}$ cells of SI and LI, but not spleen, expressed CCR6. Thus, the CCR6 expression by FoxP3 ${ }^{+} \mathrm{T}$ cells is not the universal feature of all FoxP3 ${ }^{+} \mathrm{T}$ cells. Many memory (non-Th17) T cells also expressed CCR6 but at lower frequencies than Th17 cells. Few naive T cells expressed CCR6. Many more Th17 cells of spleen and PP than those of SI and LI expressed CCR7. CCR9 ${ }^{+}$Th17 cells were enriched in SI and, to a lesser degree, in LI. We found many Th17 cells expressed CXCR5. CXCR5 was more preferentially expressed by Th17 cells in PP, spleen, and LI than the Th17 cells of SI origin. These results show that Th17 cell subsets are highly heterogeneous in expression of trafficking receptors.

Trafficking receptor phenotype of in vitro-generated Th17 cells Th17 cells can be generated in vitro by activating naive $\mathrm{CD} 4^{+} \mathrm{T}$ cells in the presence of IL- 6 and TGF- $\beta 1$. It is a question of interest if these in vitro-generated Th17 cells would have the same phenotype as the in vivo-generated Th17 cells. We cultured naive $\mathrm{CD} 4{ }^{+} \mathrm{T}$ cells in a Th17-cell induction condition and examined the trafficking receptors expressed by the Th17 cells. We prepared also FoxP $3^{+} \mathrm{T}$ cells by culturing naive $\mathrm{CD} 4{ }^{+} \mathrm{T}$ cells with TGF- $\beta 1$ and IL-2 for comparison (Figure 3a). Even though the two cell populations were induced using the same TGF- $\beta 1$, most Th17 cells remained as $\mathrm{CD}_{103^{-}}$whereas the majority of FoxP3 ${ }^{+}$ T cells were CD103+ (Figure 3a). CD103 is the $\alpha$-subunit of the $\alpha \mathrm{E} \beta 7$ integrin, which is involved in cell-cell interaction with epithelial cells by binding to E-cadherin. ${ }^{39}$ We found that the in vitro-generated Th17 cells expressed CCR4, CCR6, and CCR7, whereas the in vitro-generated FoxP ${ }^{+}$T cells expressed CCR4 and CCR7 but not CCR6 (Figure 3b). Thus, CCR6 is the receptor that is uniquely expressed by the in vitro-generated Th17 cells compared to FoxP3 ${ }^{+}$cells.

\section{Reciprocal functions of TGF- $\beta 1$ and IL-2 in CCR6 expression by Th17 cells}

The unique CCR6 expression by Th17 cells is interesting and implies that CCR6 would be important for the Th17 cell biology. It is likely that one (or some) of the cytokines used to generate the Th17 cells is responsible for the upregulation of CCR6. We examined the functions of IL- 6 and TGF- $\beta 1$ in upregulation of CCR6. It was TGF- $\beta 1$, but not IL- 6 , that was able to induce CCR6 on T cells (Figure 4a). Importantly, IL-2, when added to the culture, effectively suppressed the expression of CCR6 on Th17 cells (Figure 4b). On the other hand, neutralizing anti- 


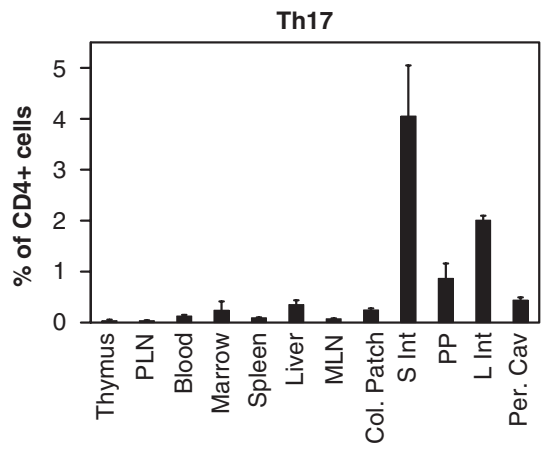

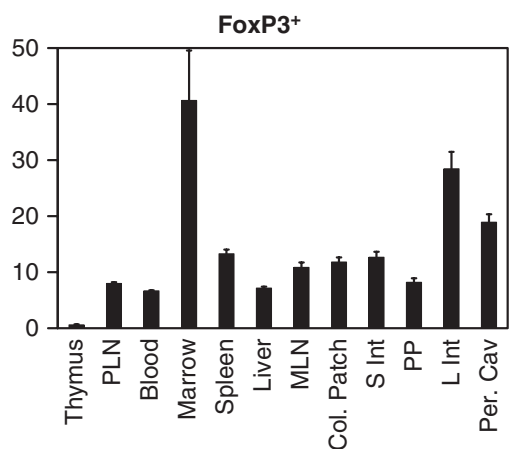

b

Th17 cells that migrated to each organ
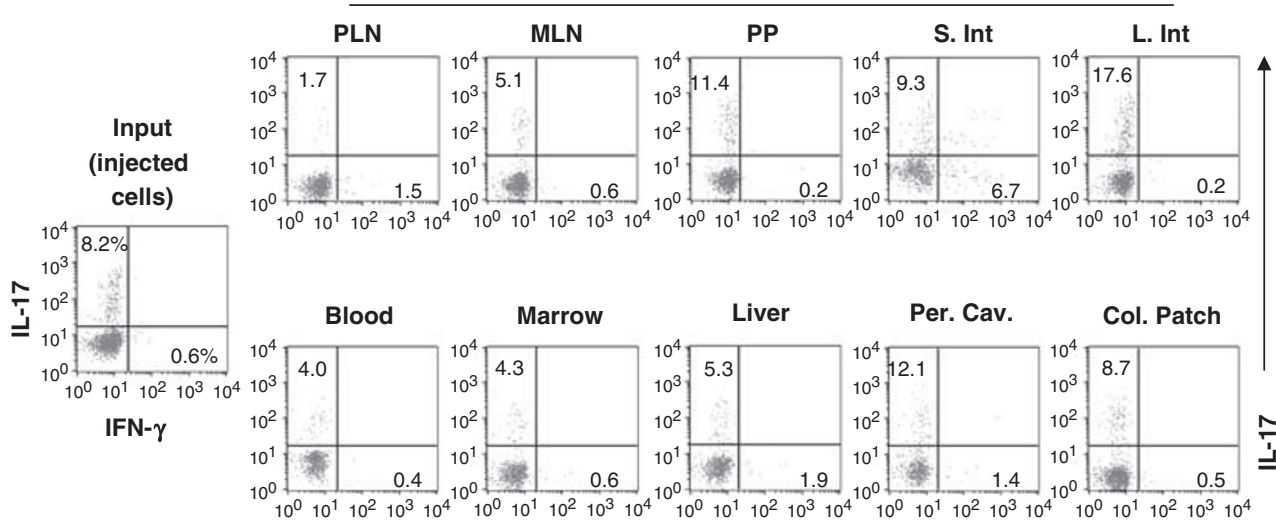

Per. Cav.

Col. Patch

IFN- $\gamma$

C
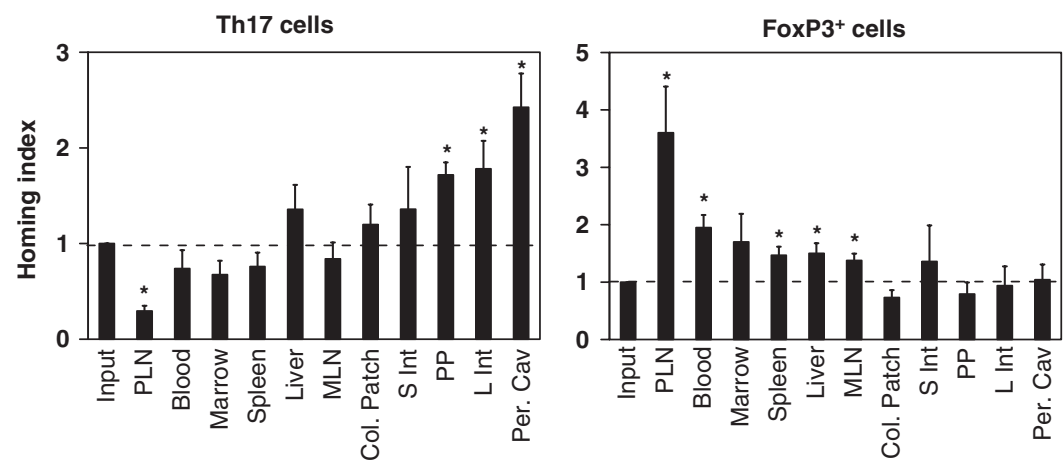

Figure 1 Tissue distribution of Th17 cells and homing capacity of in vitro-generated Th17 cells in normal mice. (a) Frequencies (\%) of Th17 cells among the $\mathrm{CD}^{+}{ }^{+}$cells of the selected organs of normal BALB/c mice. Thymus, blood, spleen, mesenteric lymph nodes (MLN), peripheral lymph nodes (PLNs: inguinal, auxiliary, and brachial), colonic patches (Col. Patch), Peyer's patches (PPs), small intestine, large intestine (L. Int.), bone marrow (marrow), and liver were examined. (b, c) Short-term homing capacity of in vitro-generated Th17 cells. Naive CD4 ${ }^{+} \mathrm{T}$ cells, isolated from the spleen of D011.10 rag2 (-/-) mice, were cultured in a Th17 cell induction condition (OVA $323-339$, TGF- $\beta 1$, IL-6, IL-1 $\beta$, TNF- $\alpha$, IL-21, and IL-23) or Treg induction condition (IL-2 and TGF- $\beta 1$ ) for 7 days. In vitro-generated Th17 cells and FoxP3 ${ }^{+}$T cells were injected into a tail vein of host mice. Mice were killed $20 \mathrm{~h}$ later and organs were harvested to determine the homing behavior of KJ1.26+ Th17 cells vs. KJ1.26+ FoxP3 ${ }^{+}$cells. A representative set of dot plot data is shown in $\mathbf{b}$. The homing behavior is shown as homing index in $\mathbf{c}$. Homing index $=\left(\right.$ injected Th17 cells or FoxP $3^{+}$cells in organ $\left.\mathrm{A}\right) \div($ total injected CD4 ${ }^{+}$cells in organ A)/(Th17 cells or FoxP3 ${ }^{+}$cells in input) $\div$(total CD4 ${ }^{+}$cells in Input). *Significant difference from the input. Averages of the data obtained from five different experiments are shown.

IL-2 antibody enhanced the CCR6 expression by Th17 cells (Figure 4b). The effects of the two cytokines on Th17-cell expression of CCR6 were dose dependent (Supplementary Figure 3a). Similarly, IL-2 was able to suppress CCR6 expression by FoxP3 ${ }^{+}$T cells (Supplementary Figure $3 \mathbf{b}$ ).

We further investigated if TGF- $\beta 1$ is required for CCR6 expression on Th17 cells in vivo by examining the phenotype of the T cells isolated from DN-TGF-RII mice. DN-TGF-RII mice express a dominant-negative form of TGF- $\beta$-RII in T cells and, therefore, the $\mathrm{T}$ cells from these mice are defective in responding to TGF- $\beta .{ }^{40}$ As shown in Figure $4 \mathbf{c}$ and reported previously by others, ${ }^{41}$ Th17 cells were decreased in numbers in DN-TGF-RII mice, but there were still some Th17 cells which were detectable in many organs (Figure 4c). The CCR6 expression by the Th17 


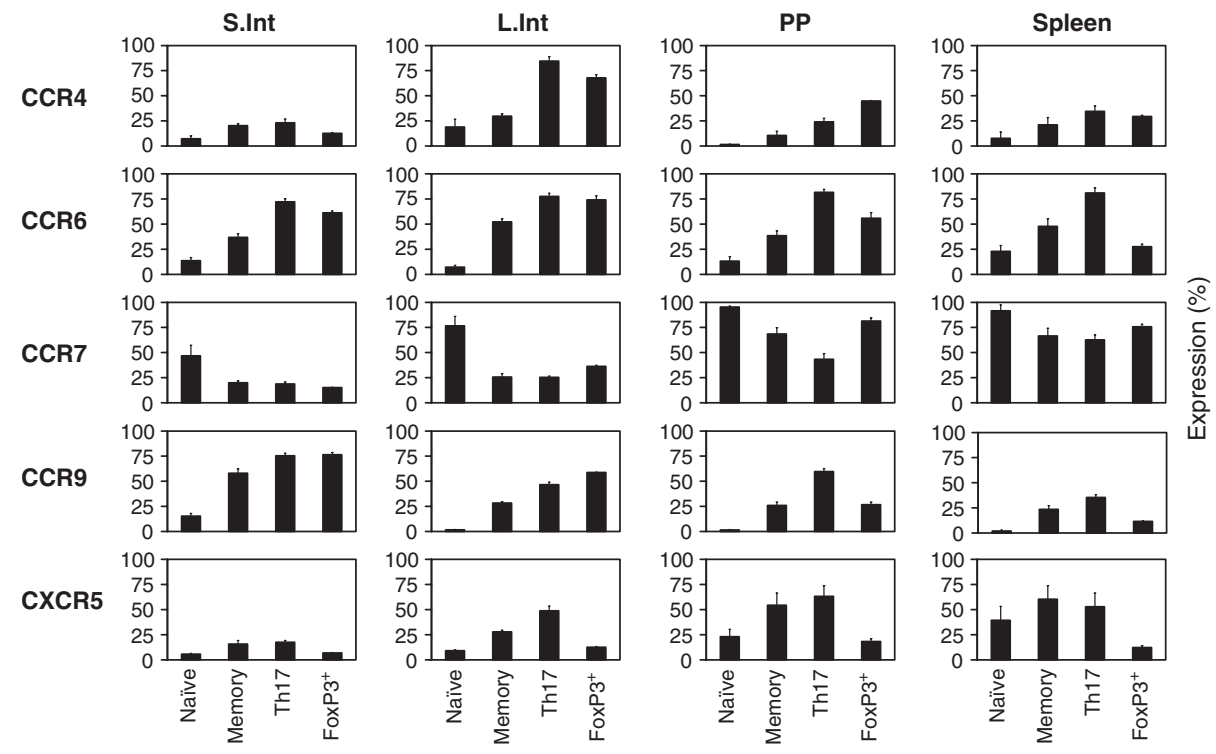

Figure 2 The chemokine receptors expressed by Th17 cells that were naturally generated in vivo. Expression of selected chemokine receptors by Th17 cells in spleen, Peyer's patches, and lamina propria of small and large intestine. Other CD4+ $4^{+}$-cell subsets $\left(\mathrm{CD} \mathrm{LL}^{+} \mathrm{CD} 44^{-}\right.$naive, $^{\mathrm{CD}} 62 \mathrm{~L}^{-} \mathrm{CD} 44^{+}$ non-Th17 memory, and FoxP3 $3^{+}$cells) were also included for comparison. Combined data from three independent experiments are shown. Cells isolated from 2 to 3 mice were pooled for each experiment.

cells, isolated from spleen, SI, and LI of DN-TGF-RII mice, was clearly decreased compared to those of wild-type mice. This information strongly supports the positive function of TGF- $\beta 1$ in up-regulation of CCR6 on Th17 cells. However, the CCR6 expression by the PP T cells of DN-TGF-RII mice was not decreased; and the CCR6 expression by CD44- non-Th17 cells in PP and LI of DN-TGF-RII mice was somewhat increased.

\section{ROR- $\gamma$ t has a limited function in the CCR6 expression by Th17 cells}

ROR- $\gamma \mathrm{t}$ is associated with the naive T-cell differentiation into Th17 cells. We examined if this orphan nuclear receptor is involved also in induction of CCR6 expression by Th17 cells. We expressed ROR- $\gamma \mathrm{t}$ in T cells using a retroviral method ${ }^{42}$ and cultured the cells in a Th17 cell differentiation condition. As expected, most of the $\mathrm{IL}-17^{+} \mathrm{T}$ cells were found within the $\mathrm{GFP}^{+}$cell (representing ROR- $\gamma \mathrm{t}^{+}$) but not the GFP ${ }^{-}$T-cell population. The $\mathrm{GFP}^{+} \mathrm{IL}_{-1} 17^{+} \mathrm{T}$ cells most highly expressed CCR6. $\mathrm{GFP}^{+} \mathrm{IL}^{-17^{-}} \mathrm{T}$ cells did express CCR6 but at somewhat lower frequencies. Most $\mathrm{GFP}^{-} \mathrm{IL}-17^{-} \mathrm{T}$ cells did not express CCR6 (Supplementary Figure 4a). Thus, ROR- $\gamma \mathrm{t}$ appears to play a positive function in expression of CCR6 in Th17 cells.

One caveat with the retroviral transduction study is that only well-activated $\mathrm{T}$ cells are likely to get transduced by the retrovirus and express GFP, and CCR6 can be preferentially expressed by only the well-activated $\mathrm{T}$ cells. To rule out this possibility, we employed ROR- $\gamma \mathrm{t}$ transgenic mice. Using this system, we further determined the impact of ROR- $\gamma$ t on CCR6 expression by Th17 cells and non-Th17 cells in vivo. The ROR- $\gamma \mathrm{t}$ transgenic mice express ROR- $\gamma \mathrm{t}$ and GFP under the control of the CD4 promoter. ${ }^{43}$ Almost all GFP ${ }^{+} \mathrm{IL}^{-17^{+}}$cells expressed CCR6, whereas most GFP ${ }^{+} \mathrm{IL}^{-17^{-}}$cells did not express CCR6 (Supplementary
Figure $4 \mathbf{b}$ ). This is somewhat different from the data obtained in vitro with retroviral transduction (Supplementary Figure 4a). The frequency of CCR6 ${ }^{+}$cells among $\mathrm{GFP}^{+} \mathrm{IL}-17^{+}$cells was higher than that of $\mathrm{GFP}^{-} \mathrm{IL}-17^{+}$cells, and the frequency of CCR6 ${ }^{+}$cells among $\mathrm{GFP}^{+} \mathrm{IL}^{-17^{-}}$cells was higher than that of GFP ${ }^{-}$IL-17- ${ }^{-} 4^{+}$T cells. Thus, ROR- $\gamma \mathrm{t}$ expression has a small positive effect on the CCR6 expression in some T cells but does not guarantee, by itself, the expression of CCR6 in all ROR- $\gamma \mathrm{t}^{+} \mathrm{T}$ cells in vivo.

\section{CCR6 is required for normal migration of Th17 cells and} prevention of excessive colonic inflammation

To gain insights into the function of CCR6 in Th17 cells' tissue tropism, we employed CCR6 $(-/-)$ mice. We examined the Th17 cell distribution in various organs of CCR6 $(-/-)$ and wild-type mice (Figure 5a and b). CCR6 (-/-) Th17 cells were specifically decreased in numbers in PPs. This alteration of T-cell distribution due to CCR6 deficiency appears to be more specific for Th17 cells than FoxP3 ${ }^{+} \mathrm{T}$ cells as there are no statistically significant differences in the FoxP $3^{+} \mathrm{T}$-cell distribution between CCR6 $(+/+)$ and CCR6 $(-/-)$ mice.

The specific decrease of Th17 cells in the PP of CCR6 (-/-) mice suggests that CCR6 may act as the homing receptor for PP. We overexpressed CCR6 in T cells by retroviral transfer of the mouse CCR6 gene and determined if CCR6, indeed, has the function as the homing receptor for PP (Figure 6a). The T cells migrated to CCL20 in a manner dependent on the level of green fluorescent protein (GFP) (CCR6) expression (Figure 6b). $\mathrm{GFP}^{+} \mathrm{T}$ cells, when injected into normal hosts, were highly efficient in migration to PP compared to $\mathrm{GFP}^{-} \mathrm{T}$ cells (Figure 6c). This demonstrates that CCR6 is the trafficking receptor that guides T-cell migration to PP and explains, in part, why 
a

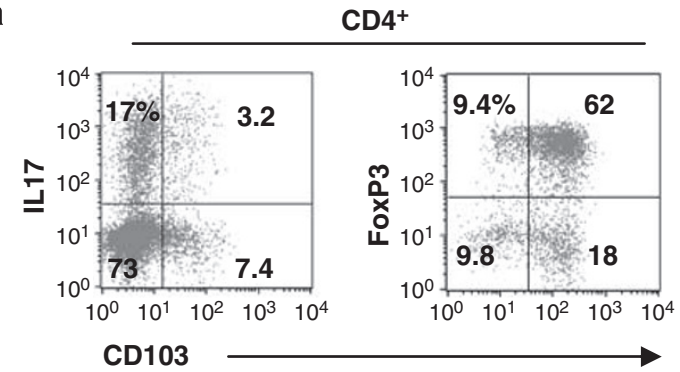

b
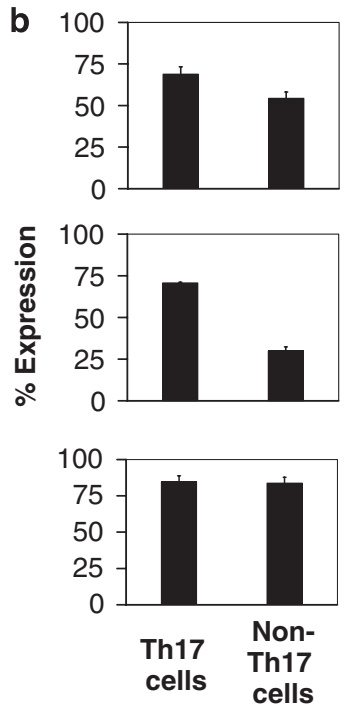
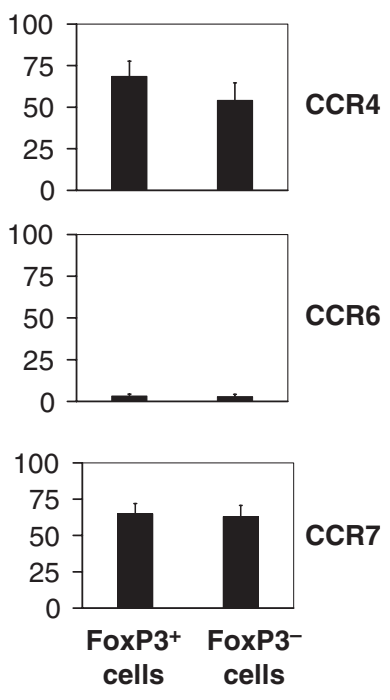

Figure 3 Trafficking receptors of in vitro-generated Th17 cells. (a) Phenotype of in vitro-generated FoxP $3^{+} \mathrm{T}$ cells and Th17 cells. Naive $\mathrm{CD}^{+}{ }^{+} \mathrm{T}$ cells, isolated from mouse spleen and lymph nodes, were differentiated in a Th17 cell induction condition (TGF- $\beta 1$, IL-6, IL-1 $\beta$, TNF- $\alpha$, IL-21, and IL-23) or in a FoxP3 ${ }^{+}$T-cell induction condition with IL2 and TGF- $\beta 1$ for 7 days. (b) The expression of chemokine receptors by FoxP3 ${ }^{+}$, FoxP3- ${ }^{-} \mathrm{IL}_{-17^{+}}$(Th17 cells), and IL-17- (non-Th17 cells) CD4+ cells was compared. Combined data $(n=3)$.

there was a selective decrease of Th17 cells in PP. The real-time PCR examination demonstrated that CCL20 is specifically expressed in PP at the highest level and in colonic patches (Col. Patch) and omentum at lower levels (Figure 6d). We generated Th17 cells from the naive CD4 ${ }^{+} \mathrm{T}$ cells (isolated from CCR6 $(-/-)$ mice and wild-type mice) for a short-term homing study (Figure 6e). The migration of CCR6 (-/ - ) Th17 cells to the PP was decreased compared to wild-type Th17 cells (Figure 6e). In addition, CCR6 ( - / - ) Th17 cells were less efficient in migration to small intestinal lamina propria and PC. Short-term migration of CCR6 $(-/-)$ Th17 cells to the LI of the normal hosts was not decreased.

To compare the effector functions of wild-type and CCR6 $(-/-)$ Th17 cells in inducing intestinal inflammation, the two Th17-cell populations were injected into Rag1 ( / - ) severe combined immunodeficiency (SCID) mice (Figure 7). Injection of the wild-type Th17 cells decreased their weight due to intestinal inflammation as expected. Interestingly, CCR6 (-/ - ) Th17 cells induced greater weight loss in the SCID mice (Figure 7a). Consistently, more severe intestinal inflammation as evidenced

by mucosal hyperplasia and infiltration with mononuclear and polymorphonuclear cells in the intestine of SCID mice transferred with CCR6 (-/ - ) Th17 cells vs. wild-type Th17 cells was observed (Figure $7 \mathbf{b}$ and $\mathbf{c}$ ). When the distribution of $\mathrm{T}$ cells was examined in situ in the inflamed lamina propria of the SCID mice injected with CCR6 $(-/-)$ Th17 cells or wild-type Th17 cells, we found the T cells were differentially localized in the two groups of mice. Wild-type T cells were found localized in the isolated lymphoid follicles/patches and crypt side of the intestinal mucosa, whereas CCR6 (-/ - ) T cells were evenly scattered throughout the entire intestinal mucosa (Figure 7d).

We examined also the frequencies of effector or suppressor $\mathrm{T}$ cells to find potential explanations for the increased inflammation in the SCID mice injected with CCR6 (-/ - ) Th17 cells. Significantly fewer Th17 cells were found in the intestine of the SCID mice injected with CCR6 $(-/-)$ Th17 cells compared to wild-type Th17 cells (Figure 8a). In contrast, Th1 cells were significantly increased in frequency in the intestine of SCID mice injected with CCR6 $(-/-)$ Th17 cells (Figure 8b). The frequencies of FoxP $3^{+} \mathrm{T}$ cells were low in both groups of mice but they were significantly decreased in the SCID mice injected with CCR6 (-/-) Th17 cells compared to wild-type Th17 cells (Figure $8 \mathrm{c}$ ).

\section{DISCUSSION}

We investigated the homing behavior of Th17 cells and determined the trafficking receptors of Th17 cells in the gut vs. other tissue sites. We found that Th17 cells efficiently migrate to the gut and associated tissues and express trafficking receptors in a tissue-specific manner. One receptor (CCR6) is universally expressed by all Th17-cell subsets induced in vivo and in vitro and the function of this receptor was investigated in detail. CCR6 expression is required for normal population of Th17 cells in PP. It promotes Th17-cell migration to PP and SI of normal hosts. The SCID mice injected with Th17 cells that can not express CCR6 had aberrantly increased Th1 cells spread throughout the lamina propria but decreased Th17 cells and FoxP3 ${ }^{+} \mathrm{T}$ cells, suggesting that CCR6 is involved also in regulating effector T-cell balance and distribution in inflamed intestine.

Both Th17 cells and FoxP3 ${ }^{+}$cells require TGF- $\beta 1$ in their induction, and therefore, it was expected that they share certain trafficking receptors. In this regard, the mouse Th17 cells and $\mathrm{FoxP}^{+} \mathrm{T}$ cells share the expression of CCR4, CCR6, CCR7, and CCR9. Also, the human Th17 cells and FoxP3 ${ }^{+} \mathrm{T}$ cells share many other chemokine receptors (CCR2, CCR4, CCR5, CCR6, and CCR7) as published before. ${ }^{38}$ We observed in this study that the trafficking receptors that are expressed by Th17 cells reflect the tissue source of each Th17 cell subset. For example, the Th17 cells of the SI express CCR9. Th17 cells of B-cell-rich secondary lymphoid tissues express CXCR5. Preferential loss of CCR7 by the Th17 cells of nonlymphoid tissue sites is another example.

Although Th17 cells and FoxP3 ${ }^{+}$T cells share many chemokine receptors, it is not the case in all tissue sites. For example, CCR6 is expressed by Th17 cells but by few FoxP $3^{+} \mathrm{T}$ cells in spleen. We found that TGF- $\beta 1$ is a potent inducer of 
a

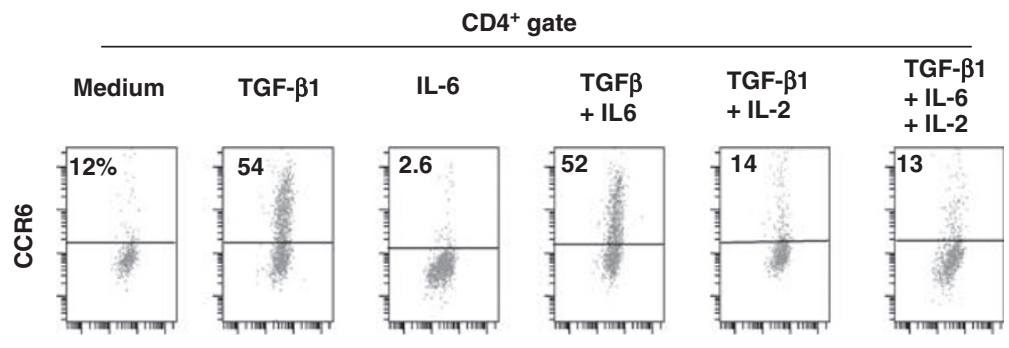

b

$\mathrm{IL}-17^{+} \mathrm{CD} 4^{+}$gate

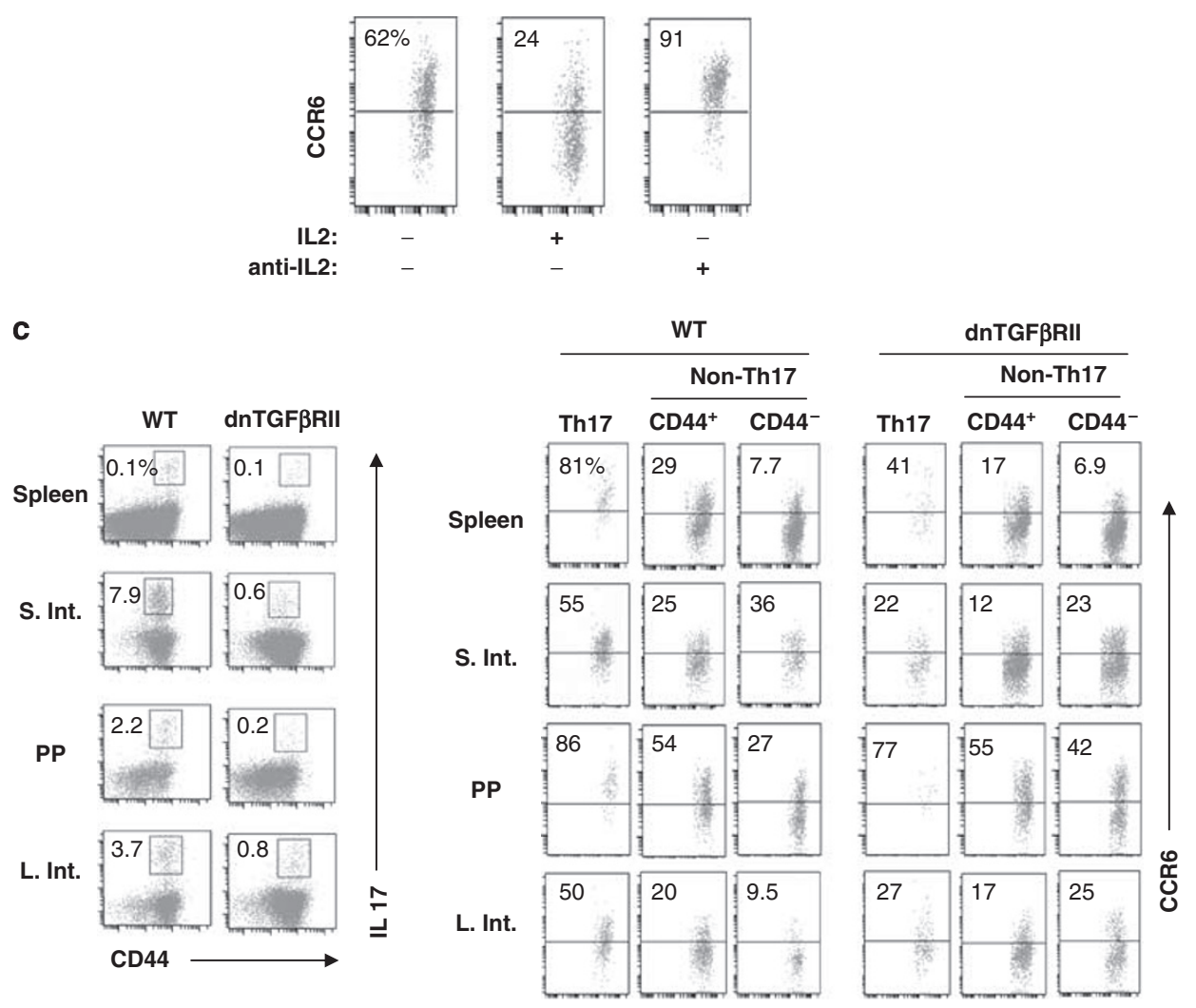

Figure 4 Factors that regulate CCR6 expression on Th17 cells. (a) Regulation of T-cell expression of CCR6 in vitro by cytokines (IL-2, TGF- $\beta 1$, and IL-6). Naive CD4+ $T$ cells were cultured with indicated cytokines for 7 days, and expression of CCR6 by the cultured CD4 ${ }^{+} T$ cells was examined. (b) Effects of IL-2 $(500 \mathrm{U} / \mathrm{ml})$ and neutralizing anti-IL-2 antibody $(10 \mu \mathrm{g} / \mathrm{ml})$ on expression of CCR6 by Th17 cells. (c) Impact of TGF- $\beta$ receptor signaling on CCR6 expression by T cells in vivo. Three CD4+ T-cell subsets, defined by the expression of IL-17 and CD44, were examined for expression of CCR6. Representative data of at least three independent experiments are shown.

CCR6 expression in T cells (Figure 4). This raises the question why only Th17 cells but not the FoxP $3^{+} \mathrm{T}$ cells express CCR6 (Figure 3). We reason that this is due to the IL-2 effect. IL-2 promotes peripheral induction of FoxP ${ }^{+} \mathrm{T}$ cells but suppresses that of Th17 cells. Importantly, IL-2 suppresses CCR6 expression by $\mathrm{T}$ cells. Thus, FoxP3 ${ }^{+} \mathrm{T}$ cells that are induced in an IL-2-rich condition would not express CCR6 because excessive IL- 2 overrides the TGF- $\beta 1$ signal in upregulation of CCR6. We observed also that the in vitro-derived Th17 cells were somewhat different from the Th17 cells generated in vivo in trafficking receptor expression. We believe that this is due to the artificially high concentrations of cytokines, particularly TGF- $\beta 1$, used for the culture. Another reason would be lack of in vivo tissue-specific signals in the in vitro culture condition.
Together with IL-6, TGF- $\beta 1$ is a major cytokine required for induction of Th17 cells. Therefore, Th17 cells are dramatically reduced in mice expressing a dominant-negative form of TGF$\beta$-RII. Small numbers of Th17 cells are still present in these mice and we found that they express CCR6 at reduced levels. This suggests that TGF- $\beta 1$ is important not only for induction of Th17 cells but also for CCR6 expression. However, the Th17 cells in PP of the transgenic mice, although dramatically reduced in numbers, still expressed CCR6 at high levels. This is puzzling but can be explained. First, there may be TGF- $\beta 1$-independent induction mechanisms for CCR6 expression in Th17 cells. A recent study on arthritogenic CCR6 ${ }^{+}$Th17 cells found that IL- 1 and lack of IL- 4 and IFN- $\gamma$ have positive functions in induction of CCR6. ${ }^{35}$ Second, the majority of CCR6 $6^{-}$Th17 cells 


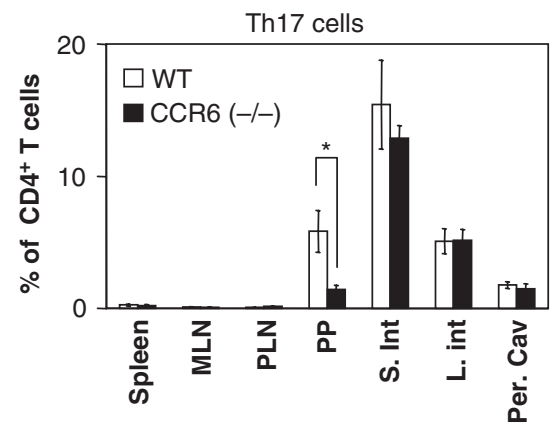

b

WT
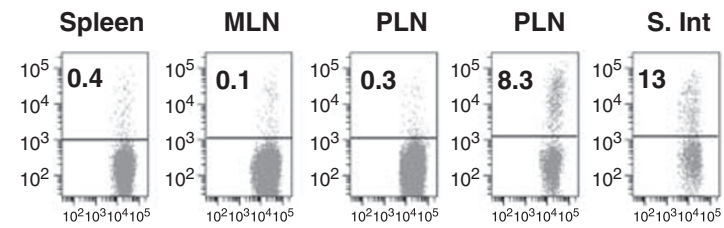

S. Int
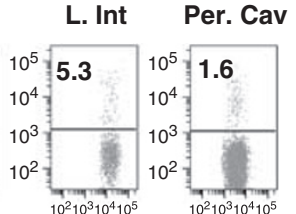

CCR6 (-l-) $\begin{gathered}10^{4} \\ 10^{3}\end{gathered}$
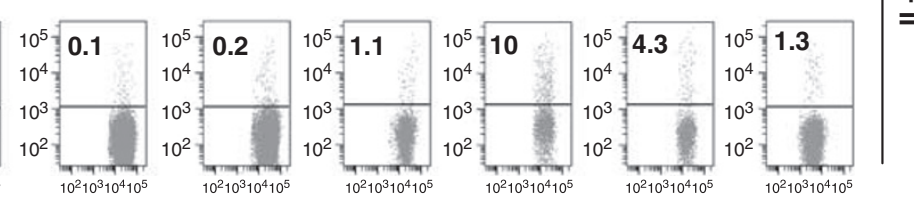

Figure 5 Th17 cells are selectively decreased in the Peyer's patches of CCR6-deficient mice. (a) The frequencies of Th17 cells and FoxP3 ${ }^{+}$CD4 ${ }^{+}$cells (control cells) in various organs of wild-type and CCR6 (-/-) mice were examined. Averages of four different mice are shown with s.e.m. *Significant differences between wild-type and CCR6 (-/-) mice (Student's $t$-test). (b) Representative dot plots are shown.

could have been released from the PP because they are lacking the PP homing receptor. Consequently, only CCR6 $6^{\text {high }}$ Th17 cells (probably induced by a TGF- $\beta$-independent mechanism) would be retained in the PP of the DN-TGF- $\beta$-RII transgenic animals. Although CCR6 expression is reduced on Th17 cells of DN-TGF- $\beta$-RII mice, it was slightly increased on some CD $44^{-}$ non-Th17 cells of DN-TGF- $\beta$-RII mice. As the T-cell activation signal is a positive factor in upregulating CCR6, we reason that this modest increase in CCR6 expression would be the result of hyperactivation of $\mathrm{T}$ cells due to TGF- $\beta 1$-signaling deficiency.

ROR- $\gamma \mathrm{t}$ is a key transcription factor for Th17 cells. The connection between ROR- $\gamma \mathrm{t}$ and Th17 cells is reminiscent of that between CCR6 and Th17 cells. This raises a question if ROR- $\gamma \mathrm{t}$ is important for CCR6 expression on Th17 cells. We found that ROR- $\gamma$ t has a positive effect on Th17-cell expression of CCR6 in vitro. In vivo, however, this effect is small and not all ROR$\gamma \mathrm{t}^{+} \mathrm{T}$ cells express CCR6. Thus, expression of ROR- $\gamma \mathrm{t}$, by itself, is not sufficient to induce CCR6 expression by Th17 cells.

We were surprised to see that Th17 cells are very different from FoxP3 ${ }^{+}$T cells in migration. For this experiment, we used in vitro generated Th17 cells, which highly expressed CCR6 but not CD103. The control T cells, used in this study, were FoxP3 ${ }^{+}$ T cells, which did not express CCR6 but expressed CD103. The Th17 cells mainly migrated to the gut and associated lymphoid tissues (e.g. PP), whereas FoxP3 ${ }^{+}$T cells migrated to most tissue sites but particularly more efficiently to the secondary lymphoid tissues and marrow. This suggests a potential function of CCR6 in Th17 migration to the gut. The function of CCR6 in Th17-cell trafficking to the gut has been unknown. We found that CCR6 deficiency led to decreased short-term migration of Th17 cells to PP, SI, and PC. The long-term effect of the CCR6 deficiency, as seen in CCR6 $(-/-)$ mice, was the decreased numbers of Th17 cells in PP. It has been reported that CCR6 $(-/-)$ mice are deficient with the $\mathrm{CD} 11 \mathrm{~b}^{+} \mathrm{CD} 11 \mathrm{c}^{+}$dendritic cell subset in subepithelial dome of PPs (where CCL20 is expressed) and have impaired humoral immune responses to rotavirus. ${ }^{44,45}$ Our results suggest that CCR6 would not be important in longterm population of Th17 cells in the lamina propria of SI in normal hosts. Long-term population of Th17 cells involves not only migration but also induction and proliferation. Thus, the normal population of Th17 cells in the intestine of CCR6 $(-/-)$ mice implies that the intestine is a site of active induction and proliferation of Th17 cells. The dominant function of CCR6 in T-cell homing to PP is well supported by our data presented in Figure $\mathbf{6 c}$. These data are consistent with the expression pattern of CCL20, which is highly expressed by PP cells (Figure 6d). It has been previously reported that epithelial cells lining PP and isolated lymphoid follicles highly express CCL20. ${ }^{46,47}$ In addition, we showed that colonic patch (a PP-like structure in colon) cells express CCL20 (Figure 6d). This information provides an explanation for the failure of the effector $\mathrm{T}$ cells derived from CCR6 $(-/-)$ Th1 cells to localize in specialized tissue sites such colonic patches and crypt side of the inflamed lamina propria (Figure 7d). We also observed that omentum (a gate to peritoneal cavity ${ }^{48}$ ) expresses CCL20, which is in line with the decreased migration of CCR6 $(-/-)$ Th17 cells to peritoneal cavity (Figure 6e).

We are not claiming that CCR6 would be the only trafficking receptor that is important for migration and localization of Th17 
a
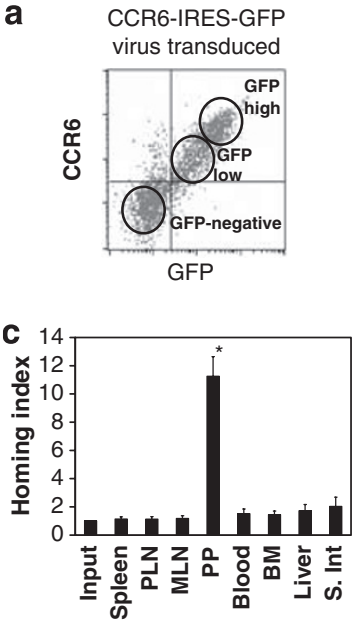

b
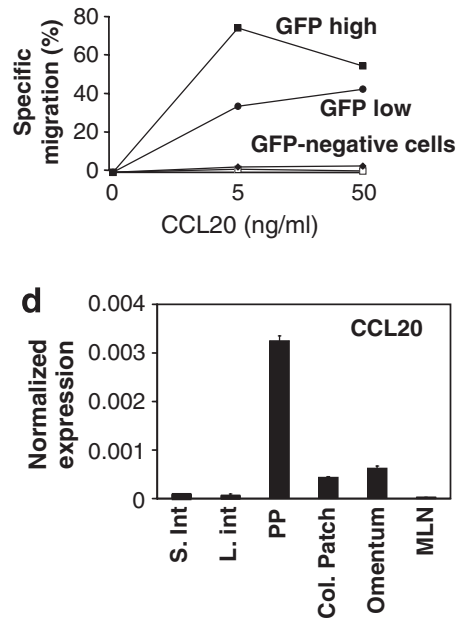

e

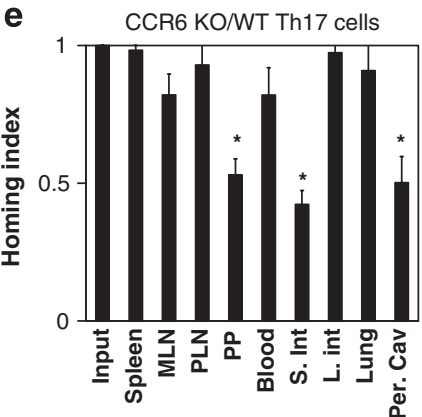

inflammatory activity of CCR6 $(-/-)$ vs. CCR6 $(+/+)$ Th17 cells showed that administration of CCR6 $(-/-)$ Th17 cells into SCID mice led to more aggressive inflammation than their wild-type counterparts. We initially suspected that CCR6 (-/ - ) Th17 cells would be less inflammatory than wild-type Th17 cells in the intestine of SCID mice. However, this appears to be not true as Th17 cell numbers were decreased in the SCID mice injected with CCR6 (-/-) Th17 cells compared to wild-type Th17 cells; and there was compensatory increase in Th1 cells which is in line with the excessive inflammation. It appears that the injected Th17 cells seem to become the inflammatory Th1 cells, a process accelerated in the absence of CCR6. Although in vitro-generated Th17 cells can induce intestinal inflammation in a certain model, ${ }^{49}$ it has been established that Th1 cells are the dominant inflammatory effector $\mathrm{T}$ cells in the colitis model that we used in this study. ${ }^{50,51}$ Thus, our results argue against that the injected Th17 cells are the major inflammatory cells for this model. In this regard, it has been documented that the Th17 cells stimulated in the presence of TGF- $\beta 1$ plus IL- 6 are not inflammatory or even antiinflammatory in an experimental encephalomyelitis model. ${ }^{52}$ It requires further studies to fully understand the connection between the functions of CCR6 in regulation of T-cell migration and in regulation of effector T-cell balance in inflamed intestine.

\section{METHODS \\ Mice}

$\mathrm{BALB} / \mathrm{c}$ mice and C57BL/6 mice were purchased from Harlan (Indianapolis, IN). CD4-TGF- $\beta$-R2 mice, expressing a dominant-negative form of the human TGF- $\beta$ receptor II (DN-TGF- $\beta$-RII) expressed under the direction of the mouse CD4 antigen promoter, ${ }^{40}$ CCR6 $(-/-)$ mice, and Rag1 ( $-/-)$ mice were obtained from the Jackson Laboratory, Bar Harbor, Maine. ROR- $\gamma$ t mice were generated as described before. ${ }^{43}$ All animal experiments were performed according to the approved protocols and institutional guidelines. Generally, the mice were used between 6 and 10 weeks of age at the start of each experiment.

\section{In vitro generation of Th17 cells}

Preparation of the cell suspensions of various tissues was performed as described before. ${ }^{42}$ Single-cell suspensions of lymph nodes (mesenteric, inguinal, auxiliary, and brachial) and spleens were prepared by grinding tissues through an iron mesh. $\mathrm{CD} 4^{+} \mathrm{T}$ cells were isolated by a CD4 ${ }^{+}$ T-cell isolation kit (Miltenyi Biotec, Auburn, CA) from BALB/c mice and further processed for isolation of $\mathrm{CD} 4^{+} \mathrm{CD} 25^{-} \mathrm{CD} 44^{-} \mathrm{CD} 69^{-}$naive T cells with an AutoMACS separator (Miltenyi Biotec). Splenocytes of DO11.10 Rag2 (-/ $)$ mice were also used for some experiments. The cells were cultured for 5-6 days in complete RPMI 1640 medium (10\% fetal bovine serum) supplemented with irradiated splenocytes (three times of T-cell numbers), concanavalin A $(2.5 \mu \mathrm{g} / \mathrm{ml})$ or OVA $323-339$ $(1.0 \mu \mathrm{g} / \mathrm{ml})$, hTGF- $\beta 1(5 \mathrm{ng} / \mathrm{ml}), \mathrm{mIL}-6(20 \mathrm{ng} / \mathrm{ml}), \mathrm{mIL}-21(10 \mathrm{ng} / \mathrm{ml})$, $\mathrm{mIL}-23(10 \mathrm{ng} / \mathrm{ml}), \mathrm{mIL}-1 \beta(10 \mathrm{ng} / \mathrm{ml})$, and $\mathrm{mTNF}-\alpha(20 \mathrm{ng} / \mathrm{ml})$, anti$\mathrm{mIL}-4(11 \mathrm{~B} 11,10 \mu \mathrm{g} / \mathrm{ml})$ and anti-mIFN- $\gamma(\mathrm{XMG} 2.4,10 \mu \mathrm{g} / \mathrm{ml})$. All cytokines were from R\&D Systems, Minneapolis, MN, or PeproTech, Rocky Hill, NJ, and the antibodies were from BioLegend, San Diego, CA, eBioscience, San Diego, CA, and/or BD Bioscience, San Diego, CA.

\section{Examination of trafficking receptor expression by Th17 cells}

Expression of chemokine receptors and adhesion molecules was examined as previously described. ${ }^{53}$ Single-cell suspensions, isolated from various organs of BALB/c, C57BL/6, CCR6 $(-/-)$, or ROR- $\gamma$ t mice, were stained with antibodies or chemokine-Fc proteins for $30 \mathrm{~min}$, followed by 
a

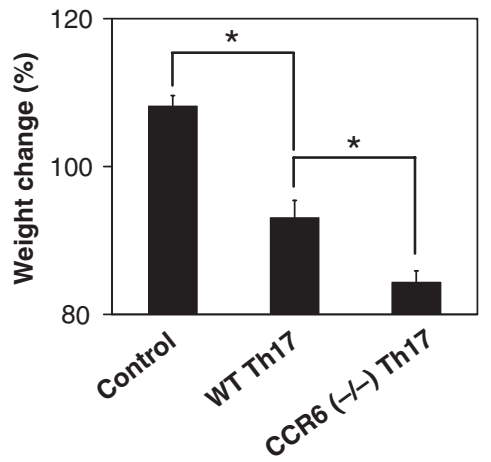

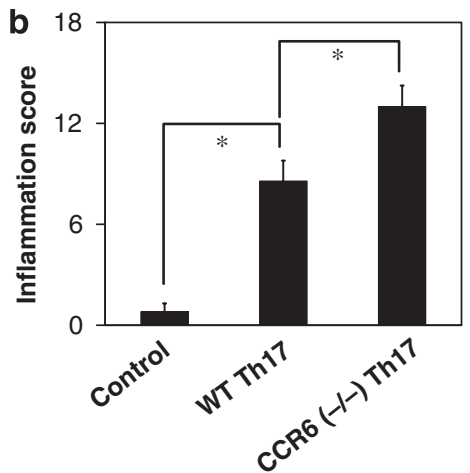

C

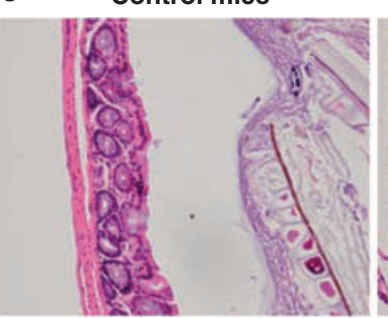

Wild-type Th17 cells

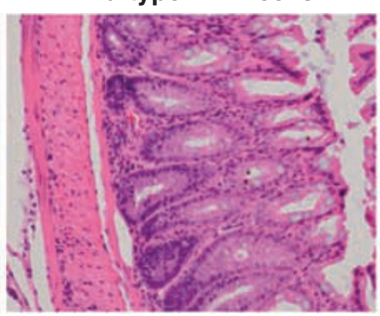

CCR6 (-I-) Th17 cells

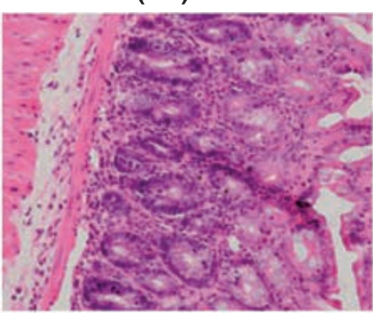

d
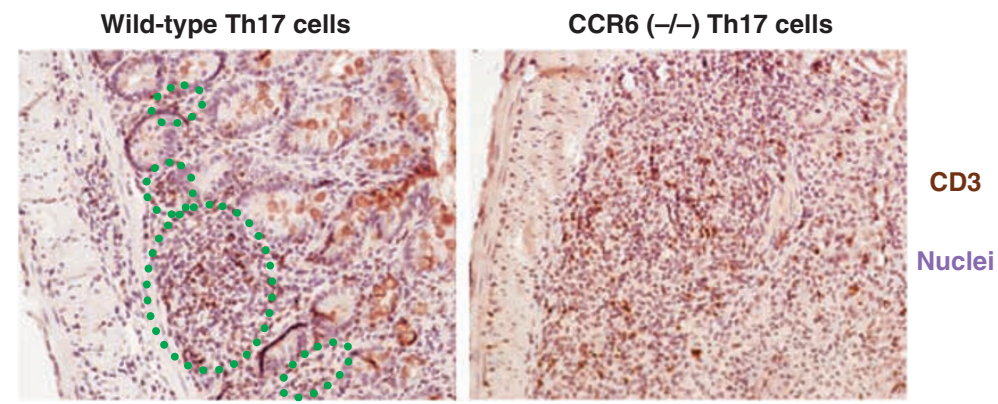

Figure 7 More severe intestinal inflammation occurs in SCID mice injected with CCR6 (-/-) Th17 cells compared to wild-type Th17 cells. Wild-type (WT) Th17 cells and CCR6 (-/-) Th17 cells, generated in vitro, were injected into Rag1 (-/-) mice to induce intestinal inflammation. (a) Weight change due to the intestinal inflammation ( $n=10-11$ per group). Results from three experiments were combined and averages are shown with s.e.m. (b) Inflammation scores of distal colon. *Significant differences $(<0.05)$ between wild-type CCR6 $(+/+)$ and CCR6 $(-/-)$ Th17 cells. (c) H\&E staining of the distal colon (magnification: $\times 200)$. (d) Distribution of T cells in the inflamed distal colon of SCID mice injected with wild-type CCR6 $(+/+)$ or CCR6 (-/-) Th17 cells. The CCR6 (+/+) T cells localized in the isolated lymphoid follicles and crypt side of the intestinal mucosa are highlighted with green circles.

staining with APC-streptavidin (BD) and antibodies to CD44 and CD4. The cells were further activated with phorbol 13-myristate 12-acetate and ionomycin for $4 \mathrm{~h}$ in the presence of monensin, fixed and permeabilized, and stained with anti-mIL-17 (BioLegend, San Diego, CA).

\section{Retroviral overexpression of CCR6 and ROR- $\gamma \mathbf{t}$}

The full open reading frame of the mouse CCR6 gene or the mouse ROR$\gamma t$ gene was amplified by reverse transcriptase-PCR and cloned into a retroviral vector containing internal ribosome entry site (IRES) and GFP. ${ }^{42}$ The DNA sequence of the CCR6 open reading frame was verified to be free of mutations. The vector was transfected into a retrovirus packaging cell line (Phoenix-ECO, ATCC, Manassas, VA) and the resulting recombinant virus in the culture supernatant was used to overexpress CCR6 in T cells as described before. ${ }^{42} \mathrm{~T}$ cells were activated for $36 \mathrm{~h}$ with IL-2 and concanavalin A and spin infected. T cells were harvested 6-7 days later, examined for CCR6 expression, and used for the chemotaxis assay and homing study as described before. ${ }^{53}$

\section{Short-term migration of Th17 cells}

Naive CD4 ${ }^{+} \mathrm{T}$ cells of DO11.10. Rag2 $(-/-)$ mice, wild-type, and CCR6 (-/ $)$ mice were cultured to generate Th17 cells or FoxP3 ${ }^{+}$cells.
The method for in vitro generation of Th17 cells is described above. For T cells from DO11.10 Rag2 (-/-) mice, OVA ${ }_{323-339}$ was used to activate T cells. For T cells from other mice, concanavalin A $(2.5 \mu \mathrm{g} / \mathrm{ml})$ or phytohemagglutinin $(5 \mu \mathrm{g} / \mathrm{ml})$ was used. FoxP3 ${ }^{+}$cells were prepared by culturing cells in complete RPMI 1640 medium $(10 \%$ fetal bovine serum) supplemented with hIL-2 (100 U/ml) and hTGF$\beta 1$ ( $5 \mathrm{ng} / \mathrm{ml}$; R\&D Systems). Th17 cells and FoxP $3^{+}$cells $\left(\sim 10^{7}\right.$ cells per mouse) were injected together into $\mathrm{BALB} / \mathrm{c}$ mice through a tail vein. The host mice were killed $20 \mathrm{~h}$ later, and indicated organs were harvested. The KJ-1.26 ${ }^{+} \mathrm{Th} 17^{+}$and $\mathrm{KJ}-1.26^{+}$FoxP3 ${ }^{+}$cells that migrated to various tissue sites were identified with flow cytometry using anti-DO11.10 TCR (KJ-1.26), anti-mIL-17A (TC11-18H10.1) and anti-FoxP3 Ab (FJK-16s). For homing of CCR6 (-/ - ) Th17 cells, wild-type and CCR6 $(-/-)$ Th17 cells were labeled differently with carboxyfluorescein succinimidyl ester (CFSE) and tetramethylrhodamine isothiocyanate (TRITC) as described before ${ }^{53}$ and injected into a tail vein of C57BL/6 mice. The absolute numbers of T cells that migrated to various organs were determined as described before. ${ }^{53}$ We also normalized the absolute numbers of the $\mathrm{T}$ cells present in each organ with that of the injected cells to obtain a parameter termed 'homing index. ${ }^{53}$ 
WT

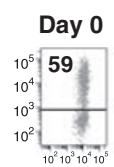

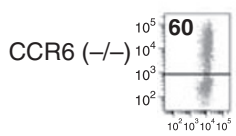

b

WT

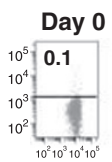

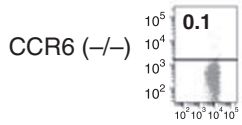
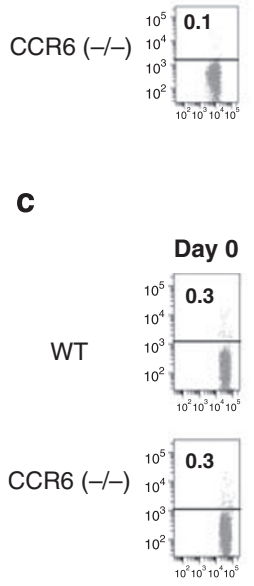
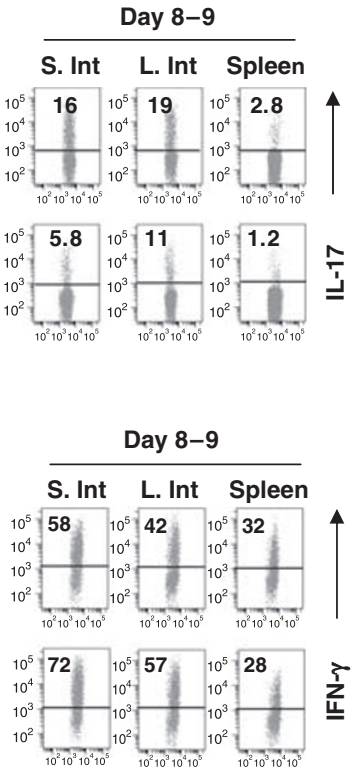

Day 8-9
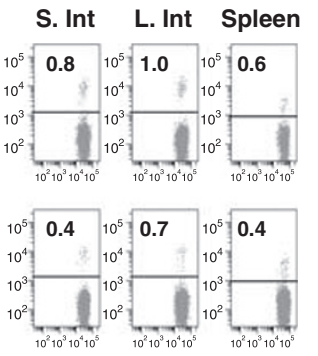
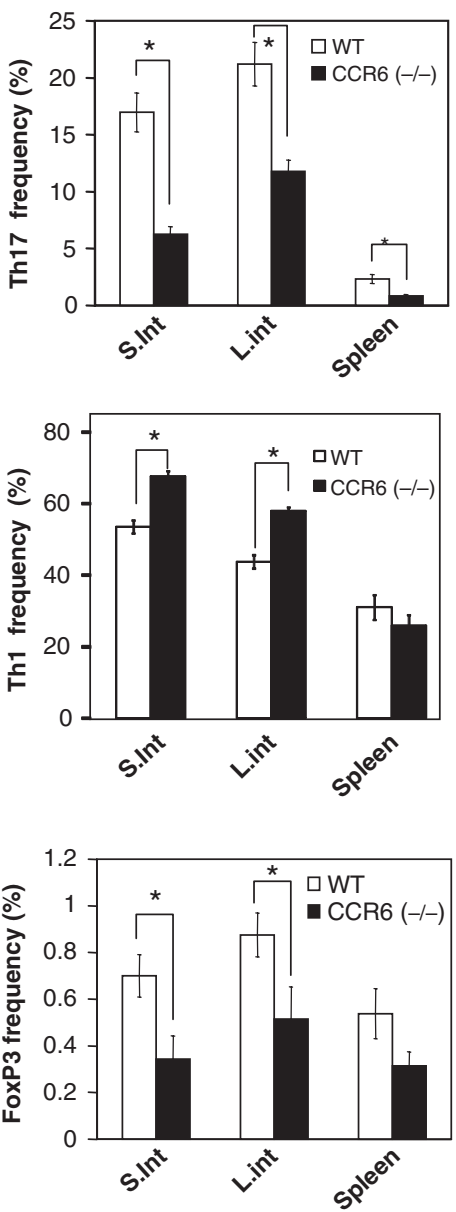

Figure 8 Aberrant T-cell balance in the intestine of SCID mice injected with CCR6 $(-/-)$ Th17 cells compared to wild-type Th17 cells. The frequencies of (a) Th17 cells, (b) Th1 cells, and (c) FoxP3 ${ }^{+}$T cells in the intestine and spleen of SCID mice injected with WT CCR6 (+/+) or CCR6 (-/-) Th17 cells were determined. ${ }^{*}$ Significant differences $(<0.05)$ between wild-type CCR6 $(+/+)$ and CCR6 $(-/-)$ Th17 cells $(n=7-8$ per group).

Induction of colitis in SCID mice and immunohistochemistry Th17 cells were generated in vitro in the Th17-cell induction condition as described above from wild-type and CCR6 $(-/-)$ naive T cells. The wild-type and CCR6 ( - / - ) Th17 cells were injected i.p. into SCID mice ( 2 million per mouse) to induce colitis. Mice were weighed every 2 days, and all mice were killed when the average weight of any group reached $\sim 85 \%$ of original weight (which took 8-24 days). Intestinal tissues were fixed in 10\% formalin, and stained with hematoxylin and eosin for histological analysis as described previously. ${ }^{42}$ Briefly, the inflammation score was obtained by combining severity scores ( 0 , no inflammation; 1 , slight infiltration of inflammatory cells in the lamina propria; 2 , moderate infiltration with inflammatory cells with mild mucosa hyperplasia; 3 , marked infiltration with inflammatory cells with disturbed mucosal architecture, crypt abscesses, and marked hyperplasia; 4, massive infiltration with inflammatory cells with severe mucosa hyperplasia) and area scores ( 0 , no area affected; 1 , $1-25 \% ; 2,26-50 \% ; 3,51-75 \% ; 4,76-100 \%)$. The formalin-fixed and paraffin-embedded intestine sections were antigen retrieved with heating in $1 \mathrm{mM}$ EDTA with a microwave, dewaxed in xylene, and rehydrated in decreasing ethanol gradient. The slides were stained with anti-CD3 (clone CD3-12) followed by biotin-labeled goat-anti-rat immunoglobulin and streptavidinhorseradish peroxidase. The slides were developed with diaminobenzidin and counterstained with hematoxylin.

\section{Statistical analyses}

Averages with s.e.m. are shown in most of the figures. Student's paired $t$-test (two-tailed) was used to determine the significance of differences between two groups. $P$ values $<$ or $=0.05$ were considered significant.

SUPPLEMENTARY MATERIAL is linked to the online version of the paper at http://www.nature.com/mi

\section{ACKNOWLEDGMENTS}

This study was supported, in part, from grants from the Crohn's and Colitis Foundation of America, NIH-NIAID (R01AI074745 and R01DK076616-01), and the American Heart Association to CHK. We thank T. Fleury (Kim lab, Purdue) in her assistance in preparation of this article.

\section{DISCLOSURE}

The authors declared no conflict of interest.

(C) 2009 Society for Mucosal Immunology

\section{REFERENCES}

1. Stockinger, B. \& Veldhoen, M. Differentiation and function of Th17T cells. Curr. Opin. Immunol. 19, 281-286 (2007).

2. Weaver, C.T., Hatton, R.D., Mangan, P.R. \& Harrington, L.E. IL-17 family cytokines and the expanding diversity of effector T cell lineages. Annu. Rev. Immunol. 25, 821-852 (2007).

3. Harrington, L.E., Mangan, P.R. \& Weaver, C.T. Expanding the effector CD4 T-cell repertoire: the Th17 lineage. Curr. Opin. Immunol. 18, 349-356 (2006). 
4. Aggarwal, S., Ghilardi, N., Xie, M.H., de Sauvage, F.J. \& Gurney, A.L. Interleukin-23 promotes a distinct CD4T cell activation state characterized by the production of interleukin-17. J. Biol. Chem. 278, 1910-1914 (2003).

5. Wei, L., Laurence, A., Elias, K.M. \& O'Shea, J.J. IL-21 is produced by Th17 cells and drives IL-17 production in a STAT3-dependent manner. J. Biol. Chem. 282, 34605-34610 (2007).

6. Liang, S.C. et al. Interleukin (IL)-22 and IL-17 are coexpressed by Th17 cells and cooperatively enhance expression of antimicrobial peptides. J. Exp. Med. 203, 2271-2279 (2006).

7. Fossiez, F. et al. T cell interleukin-17 induces stromal cells to produce proinflammatory and hematopoietic cytokines. J. Exp. Med. 183, 25932603 (1996).

8. Kawaguchi, M. et al. Induction of granulocyte-macrophage colonystimulating factor by a new cytokine, ML-1 (IL-17F), via Raf I-MEK-ERK pathway. J. Allergy Clin. Immunol. 114, 444-450 (2004).

9. Henness, S. et al. IL-17A augments TNF-alpha-induced IL-6 expression in airway smooth muscle by enhancing mRNA stability. J. Allergy Clin. Immunol. 114, 958-964 (2004).

10. Brandt, K., Singh, P.B., Bulfone-Paus, S. \& Ruckert, R. Interleukin-21: a new modulator of immunity, infection, and cancer. Cytokine Growth Factor Rev 18, 223-232 (2007).

11. Korn, T. et al. IL-21 initiates an alternative pathway to induce proinflammatory $\mathrm{T}(\mathrm{H}) 17$ cells. Nature $448,484-487$ (2007).

12. Nurieva, R. et al. Essential autocrine regulation by $\mathrm{IL}-21$ in the generation of inflammatory T cells. Nature 448, 480-483 (2007).

13. Wolk, K. et al. IL-22 regulates the expression of genes responsible for antimicrobial defense, cellular differentiation, and mobility in keratinocytes: a potential role in psoriasis. Eur. J. Immunol. 36, 1309-1323 (2006).

14. Nagalakshmi, M.L., Rascle, A., Zurawski, S., Menon, S. \& de Waal Malefyt, R. Interleukin-22 activates STAT3 and induces IL-10 by colon epithelial cells. Int. Immunopharmacol. 4, 679-691 (2004).

15. Radaeva, S., Sun, R., Pan, H.N., Hong, F. \& Gao, B. Interleukin 22 (IL-22) plays a protective role in T cell-mediated murine hepatitis: IL-22 is a survival factor for hepatocytes via STAT3 activation. Hepatology 39, 1332-1342 (2004).

16. Wolk, K. et al. IL-22 induces lipopolysaccharide-binding protein in hepatocytes: a potential systemic role of IL-22 in Crohn's disease. J. Immunol. 178, 5973-5981 (2007).

17. Veldhoen, M., Hocking, R.J., Atkins, C.J., Locksley, R.M. \& Stockinger, B. TGFbeta in the context of an inflammatory cytokine milieu supports de novo differentiation of IL-17-producing T cells. Immunity 24, 179-189 (2006).

18. Bettelli, E. et al. Reciprocal developmental pathways for the generation of pathogenic effector TH17 and regulatory T cells. Nature 441, 235-238 (2006).

19. Manel, N., Unutmaz, D. \& Littman, D.R. The differentiation of human $T(H)-17$ cells requires transforming growth factor-beta and induction of the nuclear receptor RORgammat. Nat. Immunol. 9, 641-649 (2008).

20. Volpe, E. et al. A critical function for transforming growth factor-beta, interleukin 23 and proinflammatory cytokines in driving and modulating human T(H)-17 responses. Nat. Immunol. 9, 650-657 (2008).

21. Nishihara, M. et al. IL-6-gp130-STAT3 in T cells directs the development of IL-17+ Th with a minimum effect on that of Treg in the steady state. Int. Immunol. 19, 695-702 (2007).

22. Mathur, A.N. et al. Stat3 and Stat4 direct development of IL-17-secreting Th cells. J. Immunol. 178, 4901-4907 (2007).

23. Ivanov, II et al. The orphan nuclear receptor RORgammat directs the differentiation program of proinflammatory IL-17+ Thelper cells. Cell 126, 1121-1133 (2006).

24. Yang, X.O. et al. T Helper 17 Lineage Differentiation Is Programmed by Orphan Nuclear Receptors RORalpha and RORgamma. Immunity 28, 29-39 (2008).

25. Eberl, G. et al. An essential function for the nuclear receptor RORgamma(t) in the generation of fetal lymphoid tissue inducer cells. Nat. Immunol. 5, 64-73 (2004).

26. Kurebayashi, S. et al. Retinoid-related orphan receptor gamma (RORgamma) is essential for lymphoid organogenesis and controls apoptosis during thymopoiesis. Proc. Natl. Acad. Sci. USA 97, 10132-10137 (2000).

27. Sun, Z. et al. Requirement for RORgamma in thymocyte survival and lymphoid organ development. Science 288, 2369-2373 (2000).

28. Batten, M. et al. Interleukin 27 limits autoimmune encephalomyelitis by suppressing the development of interleukin 17-producing T cells. Nat. Immunol. 7, 929-936 (2006).
29. Stumhofer, J.S. et al. Interleukin 27 negatively regulates the development of interleukin 17-producing Thelper cells during chronic inflammation of the central nervous system. Nat. Immunol. 7, 937-945 (2006).

30. Laurence, A. et al. Interleukin-2 signaling via STAT5 constrains T helper 17 cell generation. Immunity 26, 371-381 (2007).

31. Coombes, J.L. et al. A functionally specialized population of mucosal CD103+ DCs induces Foxp3+ regulatory T cells via a TGF-beta and retinoic acid-dependent mechanism. J. Exp. Med. 204, 1757-1764 (2007).

32. Denning, T.L., Wang, Y.C., Patel, S.R., Williams, I.R. \& Pulendran, B. Lamina propria macrophages and dendritic cells differentially induce regulatory and interleukin 17-producing T cell responses. Nat. Immunol. 8, 1086-1094 (2007).

33. Acosta-Rodriguez, E.V., Napolitani, G., Lanzavecchia, A. \& Sallusto, F. Interleukins 1 beta and 6 but not transforming growth factor-beta are essential for the differentiation of interleukin 17-producing human Thelper cells. Nat. Immunol. 8, 942-949 (2007).

34. Annunziato, F. et al. Phenotypic and functional features of human Th17 cells. J. Exp. Med. 204, 1849-1861 (2007).

35. Hirota, K. et al. Preferential recruitment of CCR6-expressing Th17 cells to inflamed joints via CCL20 in rheumatoid arthritis and its animal model. J. Exp. Med. 204, 2803-2812 (2007).

36. Sato, W., Aranami, T. \& Yamamura, T. Cutting edge: human Th17 cells are identified as bearing CCR2+CCR5-phenotype. J. Immunol. 178, 7525-7529 (2007).

37. Singh, S.P., Zhang, H.H., Foley, J.F., Hedrick, M.N. \& Farber, J.M. Human $T$ cells that are able to produce IL-17 express the chemokine receptor CCR6. J. Immunol. 180, 214-221 (2008).

38. Lim, H.W., Lee, J., Hillsamer, P. \& Kim, C.H. Human Th17 cells share major trafficking receptors with both polarized effector $\mathrm{T}$ cells and FOXP3+ regulatory T cells. J. Immunol. 180, 122-129 (2008).

39. Cepek, K.L. et al. Adhesion between epithelial cells and T lymphocytes mediated by E-cadherin and the alpha E beta 7 integrin. Nature 372, 190-193 (1994).

40. Gorelik, L. \& Flavell, R.A. Abrogation of TGFbeta signaling in T cells leads to spontaneous T cell differentiation and autoimmune disease. Immunity 12, 171-181 (2000).

41. Mangan, P.R. et al. Transforming growth factor-beta induces development of the $\mathrm{T}(\mathrm{H}) 17$ lineage. Nature $441,231-234$ (2006).

42. Kang, S.G. et al. Identification of a chemokine network that recruits FoxP3(+) regulatory T cells into chronically inflamed intestine. Gastroenterology 132, 966-981 (2007).

43. Xie, H., Sadim, M.S. \& Sun, Z. RORgammat recruits steroid receptor coactivators to ensure thymocyte survival. J. Immunol. 175, 3800-3809 (2005).

44. Varona, R. et al. CCR6-deficient mice have impaired leukocyte homeostasis and altered contact hypersensitivity and delayed-type hypersensitivity responses. J. Clin. Invest. 107, R37-45 (2001).

45. Cook, D.N. et al. CCR6 mediates dendritic cell localization, lymphocyte homeostasis, and immune responses in mucosal tissue. Immunity 12, 495-503 (2000).

46. Tanaka, Y. et al. Selective expression of liver and activation-regulated chemokine (LARC) in intestinal epithelium in mice and humans. Eur J. Immunol. 29, 633-642 (1999).

47. McDonald, K.G. et al. CC chemokine receptor 6 expression by $B$ lymphocytes is essential for the development of isolated lymphoid follicles. Am. J. Pathol. 170, 1229-1240 (2007).

48. Ansel, K.M., Harris, R.B. \& Cyster, J.G. CXCL13 is required for B1 cell homing, natural antibody production, and body cavity immunity. Immunity $16,67-76$ (2002).

49. Elson, C.O. et al. Monoclonal anti-interleukin 23 reverses active colitis in a T cell-mediated model in mice. Gastroenterology 132, 2359-2370 (2007).

50. Neurath, M.F., Fuss, I., Kelsall, B.L., Stuber, E. \& Strober, W. Antibodies to interleukin 12 abrogate established experimental colitis in mice. J. Exp. Med. 182, 1281-1290 (1995).

51. Powrie, F. et al. Inhibition of Th1 responses prevents inflammatory bowel disease in scid mice reconstituted with CD45RBhi CD4+ T cells. Immunity 1, 553-562 (1994).

52. McGeachy, M.J. et al. TGF-beta and IL-6 drive the production of IL-17 and IL- 10 by $T$ cells and restrain $\mathrm{T}(\mathrm{H})-17$ cell-mediated pathology. Nat. Immunol. 8, 1390-1397 (2007).

53. Lee, J.H., Kang, S.G. \& Kim, C.H. FoxP3+ T cells undergo conventional first switch to lymphoid tissue homing receptors in thymus but accelerated second switch to nonlymphoid tissue homing receptors in secondary lymphoid tissues. J. Immunol. 178, 301-311 (2007). 